\title{
Transitioning, Belonging, and the Black Student Experience: A Phenomenological Study
}

Kali Morgan, PhD, Georgia Institute of Technology

Tonisha B. Lane, PhD, Virginia Tech

Jimmy Hutchful, MEd student, University of South Florida

Selene Y. Willis, Doctoral Candidate, University of South Florida

LaFrance Clarke, Jr., Doctoral Candidate, University of South Florida

The purpose of this phenomenological study was to explore the orientation and transitional experiences of Black undergraduate students at Metropolitan State University (MSU, pseudonym) an urban, public research university in the southeastern region of the United States. MSU is a unique research site for this study, as Black students' six-year graduation rates equal that of White students. Using sense of belonging as a conceptual framework, the research team collected data from 28 participants in seven focus groups throughout the 2018-2019 academic year. Findings revealed that participants experienced disparate orientation and transitional experiences, as well as a poor racial climate throughout their time at MSU. Specifically, participants noted a shortage of Black faculty, limited Black cultural programming, and a need for identity-based space. Among working with campus partners to improve the racial climate, implications for orientation professionals include recruiting professional and student staff members who represent the racial composition of the university and ensuring culturally relevant content during orientation programs.

Keywords: orientation, sense of belonging, Black college students, graduation rates 


\section{Introduction}

Over the past 70 years, institutions of higher education have become increasingly racially diverse (St. John, Daun-Barnett, \& MoronskiChapman, 2012). Yet, there are still significant gaps in retention, success, and graduation as compared to these trends in increased access (St. John et al., 2012). Sense of belonging has been known to influence academic success (Dennis, Phinney, \& Chuateco, 2005), institutional commitment (Hausmann, Schofield, \& Woods, 2007), and student retention (Strayhorn, 2019). Sense of belonging can be facilitated through students experiencing a smooth transition into college, receiving social support, and positive mentoring relationships with faculty and staff (Strayhorn, 2019; Strayhorn, Lo, Travers, \& Tillman-Kelly, 2015), all of which may be initiated through orientation and transition programs. As institutions continue to seek ways to improve the campus racial climate and enhance students' success, more research is needed to understand the lived experiences of Black college students.

There are notable gains in access for Black students in U.S. higher education, yet campus racial climates and graduation rates remain a serious concern for this population. The national average of six-year college graduation is $60 \%$ for all groups, but Black students graduate at a rate of 40\% (NCES, 2019). Nichols, Eberle-Sudre, and Welch (2016) found that many institutions are realizing strong improvements in graduation rates overall, yet these gains are not always equal across racial and ethnic groups. Though $68.5 \%$ of institutions in this study showed improvements in graduation rates for Black students as well as their overall student body, these improvements were not large enough to close historically persistent gaps in completion rates between Black and White students.

Metropolitan State University (MSU) is a unique research site for this study, as Black students' six-year graduation rates nearly equal that

\footnotetext{
${ }^{1}$ Throughout this study, we will use Black "to refer to persons with origins in any of the Black racial groups of Africa or persons with ethnic origins in the Black racial groups of the Caribbean, Central America, South America, and other regions of the world" (Museus, Palmer, Maramba, \& Davis, 2011, p. 8).
} 
of White students. This statistic stands in stark contrast to the national graduation rates. Nationally, White students' graduation rates are 24 percentage points higher than that of Black students; however, at MSU, Black and White students complete their degrees at the same rate of 73\% (NCES, 2019). Understanding the factors and experiences that support Black students' success at MSU may be critical to other institutions seeking to facilitate educational equity. Thus, the purpose of this study was to better understand the experiences of Black students at MSU through a sense of belonging framework. The research question that guided this study was: What are the lived experiences of Black students at MSU, particularly those experiences related to transitioning into and through the university? The findings from our study may help institutions with racial completion gaps improve their rates by identifying critical supports and barriers that promote or impede student success.

\section{Literature Review}

\section{Institutional Supports and Barriers}

Orientation programs are critical to student retention; they provide opportunities for social development and tools for coping in college. Through orientation programs, students build their sense of self-esteem and social support networks, both of which are important to their academic and social adjustments (Boening \& Miller, 2005). However, among the many promising attributes of orientation programs, Boening and Miller (2005) found that discussions about diversity are lacking. Based on their study of institutional leaders, they concluded that these conversations should be a part of an overall strategy designed to set expectations for new students. This study also highlighted the growing need for institutions to transition from surface-level efforts of diversity to intentional conversations surrounding diverse populations, privilege, and inclusion (Boening \& Miller, 2005).

A study exploring the impact of orientation on academic and social learning acknowledged the importance of students' initial impressions of orientation staff and racial differences in the orientation experience (Mayhew, Vanderlinden, \& Kim, 2010). Participants who perceived 
orientation staff as resourceful and approachable associated a social learning outcome with their college orientation. As the researchers put it, orientation programs "may be the first (and sometimes only) opportunities to communicate institutional priorities to students" (Mayhew et al., 2010, p. 340). To this end, they surmised that training and staff demeanor are vital to ensuring students have a satisfying experience with orientation. The researchers also noted the disparate experiences students are having in orientation (Mayhew et al., 2010). Black students are more likely to report gaining a social learning experience, while White students tend to discern an academic benefit.

Other research demonstrates that academic advisors in orientation programs can hinder, instead of support, students' transition to college. Intended outcomes for academic advising include increasing independence, particularly in decision making, as well as reflective capabilities (White \& Schulenberg, 2012). However, in a quantitative study investigating differences in the transitional experiences of Black and White college students, researchers found Black students were also more likely to utilize academic advisors in orientation programs (Zhang \& Smith, 2011). Yet, academic advisors tended to provide the least amount of help to Black students (Zhang \& Smith, 2011).

Relative to the unique transitions of students of color, Covarrubias, Gallimore, and Okagaki (2018) uncovered the strengths and weaknesses of summer bridge programs. Some of the supports included supplemental classes in English and math, intentional moments of reflection, and orientation to campus resources. Resultantly, participants gained greater independence, familiarity with the academic workload in college, and awareness of diversity resources. Though the program was successful overall, the researchers pointed out one gap in the program offerings was the dearth of attention placed on the realities of being a person of color at a predominantly White institution (PWI). In fact, $24 \%$ of the students of color reported race-related incidents once they matriculated onto the campus. As such, this study highlights the importance of discussing race and racism in summer bridge program contexts to better support the smooth transition of students of color. 


\section{Interpersonal Support}

In addition to institutional factors, college student success often hinges on creating a peer network of support (Kuh, Kinzie, Schuh, \& Whitt, 2010). These networks of supportive student groups and spaces (e.g. conferences, residence halls) are especially important for minoritized populations, including Black students (Harper, 2006; Porter \& Dean, 2015). Linder and Rodriguez (2012) found students will choose to participate in organizations or spaces only where their "whole selves" will be welcomed (p. 393). In this study, the participants, who were women of color, reiterated the need for safe spaces and expanded the definition beyond a physical space to include the personal characteristics of individuals within that safe space. These qualities included: allies with whom they "don't have to explain" their feelings (p. 393), who do not perceive their responses to hostility as "over-exaggerations" (p. 394), and who "do their own work" to examine their own identity, privilege, and the role those play in their work as allies or community members (p. 394). Baber (2012) also discovered, when seeking peer support, homogenous communities offered a source of perseverance and reduced vulnerability to assumptions connected to their racial identity. Because of these spaces, participants were able to "confront challenges to their identity, rather than internalize stereotypes and accept labels" (Baber, 2012, p.74). Faculty also play an important role in students' interpersonal support. Previous research underscores that Black faculty disproportionately meet with and mentor Black students more often than their White counterparts. In particular, Griffin and Reddick (2011) uncovered holistic and gendered support that Black faculty provide to Black students.

\section{Inhibitors to Sense of Belonging}

While a sense of belonging is key for student success, getting to the point of true belongingness is not without significant challenge. In a study examining differences between Black and White males in high school and college, researchers found that in high school, identifying as a Black man was socially positive (Wilkins, 2014). Because Black masculinity was "rare" in predominantly White high schools, Black males were seen as 
"cool" by their peers (Wilkins, 2014, p. 182). Yet, in a university setting, this same identity was continually questioned and scrutinized. This differential treatment was in stark contrast to their White peers who reported having an easier time adjusting to the college environment with little to no mention of racial identity. Implicit bias also affected peer and faculty perceptions of Black students. Wilkins (2014) found that nonBlack students avoided working in groups with Black students, and Black males perceived their peers regarded them as needing more educational supervision.

Studies on campus racial climate illustrate that Black students largely sense a hostile and unwelcoming college environment, which has implications for persistence and retention. Campbell, Carter-Sowell, and Battle (2019) explored campus climate among African American college students and found that students who reported higher levels of social isolation were less satisfied with their college experience. Results from a survey research study using both Likert-scale questions and open-ended responses revealed that students who perceived racism and discrimination less were more likely to complete their degrees (Brown, Morning, \& Watkins, 2005). Lastly, Kim et al. (2018) investigated the effect of campus climate on sense of belonging for collegians at public research universities. The results highlighted differences by race and ethnicity, particularly among African American students. For example, African American males were least likely to feel a sense of belonging compared to other racial and ethnic groups included in the study, and they were most likely to perceive the campus climate as hostile.

Clearly, Black students' experiences in college are complex. The complexities are felt academically, in trying to progress to graduation at rates similar to their peers. Socially, their experiences are complex in the exploration of identity and striving to develop a sense of belonging, which also influences their academic success. As such, a comprehensive conceptual framework is needed for this study that seeks to understand the holistic experiences of Black students at MSU. 


\section{Conceptual Framework}

The conceptual framework guiding our study was sense of belonging (Strayhorn, 2019). Specifically, Strayhorn defines sense of belonging as "students' perceived social support on campus, a feeling or sensation of connectedness, and the experience of mattering or feeling cared about, accepted, respected, valued by, and important to the campus community... such as faculty, staff, and peers" (p. 4). Sense of belonging "contains both cognitive and affective elements in that the individual's cognitive evaluation of his or her role in relation to the group results in an affective response" (Hurtado \& Carter, 1997, p. 328) and is an important variable in discussion of retention and graduation.

In particular, sense of belonging has been known to influence both academic success and institutional commitment (Dennis et al., 2005). These are two critical areas for students of color (Hausmann et al., 2007), as well as student perceptions of campus climate (Johnson et al., 2007). Sense of belonging can be facilitated through students experiencing a smooth transition (Johnson et al., 2007), receiving social support (Strayhorn, 2008), "social-community organizations" (Hurtado \& Carter, 1997), and positive mentoring relationships with faculty (Strayhorn, 2008). In addition, this framework has been used to study the experiences of students with disabilities (Vaccaro, Daly-Cano, \& Newman, 2015), international students (Glass, Kociolek, Wongtrirat, \& Lynch, 2015), and Black students (Strayhorn, 2019). Yet, several studies have found that students of color experience less sense of belonging than their White peers (Hurtado \& Carter, 1997; Johnson et al., 2007), and that lacking a sense of belonging has more critical consequences for students of color (Walton \& Cohen, 2007).

\section{Methods}

Data for this transcendental phenomenological (Moustakas, 1994) study were collected at MSU, an urban, public, research university in the southeastern region of the United States. More than 30,000 students attend this institution. While a little under $50 \%$ of the student population 
are White, Latinx students make up more than $20 \%$ of the student population. Ten percent of students identify as Black or African American students; $66 \%$ of whom identify as women. Asian American students make up less than $10 \%$ of the student population, and students who identify as two or more races comprise $4 \%$ of the student population.

We used a phenomenological approach because of its emphasis on capturing the essence of a lived experience within a particular phenomenon (Creswell, 2013). The phenomenon that guided this study was understanding the unique experiences of Black students at MSU. At the time of this study, MSU had closed the racial completion gap between Black and White students. Hence, we were interested in understanding the unique experiences of Black students given the institution's recent status. We used the sense of belonging framework to support our data collection and analysis because previous research showed that belonging experiences were critical to Black student persistence and retention (Strayhorn, 2019). However, no known study had used this framework to investigate the experiences of Black students at an institution with a reported, closed racial completion gap.

Participants were recruited via flyers posted around campus in popular student spaces and emails from on-campus departments/offices that serve Black students. Twenty-eight self-identified Black students participated in the study. Most participants were women and U.S. students (Appendix A). We recruited students from a range of academic ranks (e.g., first-year, sophomore, etc.) because we desired to draw upon the in-depth knowledge students may have had given their time within the institution. This interest also played a role in our decision to conduct focus groups in order to build upon the exchange between participants when eliciting past experiences (e.g., orientation, transitioning into and through college) (Glesne, 2016). Pseudonyms were used to mask any identifiable information about the participants.

Each student participated in one of seven, semi-structured focus groups during the 2018-2019 academic year. Focus groups lasted between 60-90 minutes, and group size ranged from 3-6 participants. The focus group protocol entailed questions concerning transitioning from 
high school or community college to MSU, belonging experiences, and facilitators or impediments to their academic success. Participants were compensated for their time with a $\$ 20$ Amazon gift card. Focus group interviews were recorded and professionally transcribed prior to analysis.

\section{Analysis, Validation, and Positionality}

The research team then engaged in first-cycle theming of the data, followed by second-cycle coding focused on significant statements (Moustakas, 1994). Significant statements are "quotes that provide an understanding of how the participants experienced the phenomenon" (Creswell, 2013, p. 82). To ensure trustworthiness, each member of the research team individually read and analyzed transcripts, and then engaged in peer debriefing. As a result, the research team developed both textural (i.e., what the participants experienced) and structural descriptions (i.e., "the context or setting that influenced how the participants experienced the phenomenon") (Creswell, 2013, p. 82). Taken together, these descriptions depict the essence of the Black student experience at MSU (Moustakas, 1994).

The research team also bracketed their own perspectives (Moustakas, 1994) and positionalities as researchers. Author 1 identifies as a White woman. Author 2 identifies as a Black woman. Other members of the research team included graduate students - Author 3, a Black man (master's student); Author 4, a Black woman (doctoral candidate); and Author 5, a Black man (doctoral candidate). Author 6 is a Hispanic woman (student affairs professional). Author 1 was always assisted by other members of the research team. The research team feels that the participants spoke candidly about their experiences, both positive and negative, despite the presence of a White woman, particularly after friendly encouragement that the conversation was a safe space and all data would remain confidential.

\section{Limitations}

In this study, we focused on Black students at one urban, public 
research university. Therefore, readers should use caution in how they interpret the transferability of the findings to other contexts and students. Given our usage of a qualitative research design, we do not intend for readers to generalize to all Black students at urban, public research universities. Additionally, at this institution, women represent approximately two-thirds of the Black student population. Though we recognize that a majority of our participants identified as cisgender women, we felt it was important to include all of the students who participated in the study as to honor their voices and perspectives regarding the phenomenon under investigation. Further, we made numerous attempts to recruit participants of all genders for this study, and we are confident that the data reflects the experiences of Black students at MSU.

\section{Findings}

Our guiding research question asked: What are the lived experiences of Black students at MSU, particularly those experiences related to transitioning into and through the university? Using sense of belonging as our conceptual framework, we identified four themes, each theme compounded upon the others: 1) disparate orientation and transitional experiences, 2) shortage of Black faculty, 3) limited Black cultural programming, and 4) a need for identity-based space. The first theme speaks to the variety of encounters participants had due to their backgrounds (e.g., first-generation college students), interactions with orientation staff, and overall perceptions of the orientation program. The remaining three themes illuminate the participants' experiences once they transitioned into college and their attitudes concerning the paucity of institutional elements that centered their identities. Findings also highlight unmet expectations of a purported diverse college environment.

\section{Disparate Orientation and Transitional Experiences}

Students reported the university's diversity served as their motivation for choosing MSU. Yet, several students were surprised about 
the apparent lack of diversity upon arrival starting with their orientation experience:

On the website, I saw that they said they have a lotta diversity and stuff like that. That was really important to me. When I came here, it was the opposite. Even at my orientation, there was literally only like four black people.

These students experienced a contrast between their expectations and lived experiences upon arrival to campus.

Similarly, participants remarked on the diversity of the orientation staff, both professionals and students. One student currently serving as an orientation leader emphasized the importance of having orientation staff be representative of the university's whole community:

...when I think about orientation as a system in which students are funneled into and exited out of, orientation is fully staffed by White people. Particularly White women with one woman who is not White, but is also not from this country and White passing. Which is totally fine, but in the grand scheme of this institution, it doesn't align with the students who go to this institution.

She went on to discuss representation among the student staff: ...then when you look at the orientation leaders, this year there is lots of Black orientation leaders. Well, a lot more than previously, but there is also very few Latinx individuals who are on our orientation team, but again... [MSU, an institution with a significantly large Latinx student population]... When those things don't align, how can students feel supported in their transition when we don't have the actual people in place to make that happen?

Other participants reported mixed experiences with the student staff. Though one participant had a Black orientation leader assigned to her small group, she reported a negative experience:

She was one of their diverse options, which I'm sure they chose because of the diversity. Her mannerisms-everything she did-was not of a diverse person.... she was very passive-aggressive. If you're expecting something from a group of people-you're supposed to be their leader. Be their leader. Tell them what to do...We all made a 
group chat separate from the one she was in, because we didn't like her so much.

In contrast, another participant described a positive experience with a Nigerian woman as her orientation leader. Another participant asserted that in general, the orientation leaders "did do a great job of being friendly and kind and welcoming us to the campus, being our friends for the time being." Finally, one participant was surprised by a positive interracial mentorship experience with a White male orientation leader:

I think overall, with my orientation, most of my orientation leaders were White, but I love one of them. Well, at least one, and I still talk to him to this day, like, he helped me apply for orientation and feel confident enough to do it. He is one of the few White men in my life that I actually say did something for me.

Though the prior participant spoke of a positive experience applying to become someone who serves new students, another student spoke of how the experience of working in a related office that also serves new students helped her feel like she belonged at MSU. Specifically, she said, "I think the first time that I felt like I actually belonged was when we had a retreat with the entire team over a weekend...That's when I was like, 'Okay, I can stick it out here at MSU.'” The team to which she was referring is an office located in student affairs that works closely with orientation (housed in academic affairs), but one that only serves new students after they complete the matriculation process.

The content of orientation also made an impression on the participants. Without prompting, participants expressed being surprised that orientation curriculum did not include information about offices, departments, and student organizations that specifically serve Black students:

I feel like a lot of things weren't explained, though...The Black organizations or just organizations in general. They didn't really cover many of those during orientation, where I feel like they should have...I never heard about [it] until this year.

Similarly, another participant expressed confusion about why this gap occurred: 
I don't know if it's any fault of their own cuz I don't know if you have to elect to be in orientation or whatever, but I know that there's people who do work in there. I have a friend that works in [Multicultural Affairs Office] but she switched to orientation just so she can put that out there...and cover bases with Black students and Black organizations and Black resources.

The participant who served as an orientation leader in the group explained why this lack of curricular inclusion matters: "When you're also not giving them resources that connect them to their identities, we're doubly hurting these students." Referring to her earlier comments pertaining to the diversity of student and professional orientation staff, this participant understood the compounded impact of both exclusionary curricular content and lack of representation in orientation staff. In short, the students perceived that they did not receive critical information regarding adjusting to college life as a person of color.

Furthermore, some participants encountered an unwelcoming, noninclusive environment with orientation campus partners. Participants described the following experiences with academic advisors:

Participant E: I personally feel like, on the same note, with advisors and stuff-even in orientation it's like that, and I feel like they look at you, and they see you tryin' to get stuff done, and they're like, "Oh."

Participant F: Hold on.

Participant G: She's angry.

Participant H: Oh, yes.

Participant G: She's angry, so we gotta be careful. In this conversation, the participants believed the advisor thought the student was angry. Thus, these participants felt a sense of chilliness and lack of support from advisors at best.

One participant had a dedicated orientation session for her involvement with Student Support Services (SSS), a federally funded program that supports the academic and social adjustments of low-income and first-generation college students. She said:

For me, I came into SSS, and they had their own separate orientation before everybody else's... Overall, it was a positive experience, I guess, 
because I already had people in the group that I knew because of SSS. I was able to interact with them the whole time... That was the fun part about it, I guess...I would say that's one of the best things that come out of orientation is the meeting the people that you can become friends.

Another student made use of the SSS support structure, even though she was not a member, by identifying a specific academic advisor who also served as an advisor for SSS:

...In high school, I had a specific counselor that I assigned myself. You're not supposed to. You're supposed to go to all of them, but I assigned one person to myself. I did the exact same thing when I got to college, because once you have somebody that you know is for you, then conversations are never lost in translation. You just have that one person that's gonna get you from point A to point B successfully. I made sure that I assigned or stole an academic advisor and basically said, "Whenever you're free, I'm free, too." That's one of the things I did. Then I took it upon myself to adopt my [first-year seminar] teacher as a mentor, because they know the campus like the back of their hand. Coincidentally, my [first-year seminar] teacher was an SSS advisor. I'm not in SSS, but I took her as another person that I just stole.

Applying what she learned about the value of a guidance counselor from high school to the college setting, this participant took initiative to seek out an advisor who would be supportive of her efforts. In this way, any success this participant experienced as a result of working closely with an advisor should be attributed directly to the participant rather than the institution.

In addition to this program, other summer bridge programs also positively impacted participants' transition to the university. One participant described a major-specific program, saying, "I think I had a pretty good first year experience. I'm still in it because ... I ... [was]... in this program in the summer. It was 30 students, but it was what, four to six weeks?" Upon successful completion of this program, participants were admitted to both the major and the major's living learning community. 
Another student referenced a different program, designed for all out-ofstate and international students. The participant expressed her optimism for the experience, but then described the racism she encountered after the initial summer program:

...with the group of friends, I went into in the fall, they were all Caucasian because the majority of them were just Caucasian in my summer program. With that being said, there were situations where they would say something that was offensive or say something out of pocket. I eventually had to drop that friend group because somebody had called me the $\mathrm{N}$-word. That was a very hard thing. I was like, “Dang, I wanna transfer from MSU." It wasn't the first experience that I had on this campus where somebody had used the N-word or referred to somebody as that, and so I was just like, "This is awful." She continued at MSU, attributing her eventual persistence and success to the Black community at MSU:

If I weren't introduced to the Black community here at MSU, I wouldn't have been as successful because I had failed a class that semester. I was going through a lot moving from Europe to here, back and all this stuff. Since I've been within the Black community, there's been a lot of people who are there to uplift you and people who are like, "Oh, you're studying. I'm gonna come study with you." “Oh, you need a hand today. I'll help you out," like take a mental-health day. People are more loving, in that sense, cuz they also experienced things like this on the campus.

Considered together, these participants' experiences with orientation and their transition to college involved an unexpected lack of diversity upon arriving at orientation, overt and covert racism, and a desire to see culturally relevant curriculum that was currently missing from the orientation program. Yet, participants could find some support with groups, such as the Black community and certain departments on campus, as well as selected persons, like an orientation leader and an intentionally chosen academic advisor. 


\section{Shortage of Black Faculty}

According to institutional data, MSU has a Black student to Black faculty ratio of 29 to 1 . Depending on the student's major it is plausible that they may never encounter a Black professor during their time in college. Consequently, one participant recounted "I have yet to have a Black professor, and I'm a senior." Another participant concurred: “...I've never had a Black professor yet. It's really sad, honestly. I thought it was gonna be more diverse, but it's not. Even on campus, I just feel like I'm surrounded by White people." While many participants lamented the lack of Black faculty, other participants described the benefits of having Black faculty. One participant spoke from a personal experience with a faculty member in Africana studies:

Dr. $[X]$ is the first teacher...in my entire Africana studies major that I've had who is actually from Africa. While all my other teachers had such amazing really great perspectives to bring to everything we had. It was just something about him not only being scholarly intelligent, but also having that own personal experience that really changed everything for me. It was just so hard, and it was something that was just so inspirational to me that it truly changed everything, and literally from just listening to this man, not even doing well in the class, but just listening.

The participant illustrates how having Black professors in the classroom environment can be transformational for Black students. She also pointed out that his excellence in teaching did not negate the efforts of White faculty in the department. All faculty were important to advancing knowledge in the content area; however, the Black professor's ability to ignite a passion for learning in this participant was unique to the educator's identity.

In another focus group, a participant explained the importance of having Black faculty in the following manner:

I think more Black professors would help because you're able to connect with them or you're able to feel more comfortable going to them saying, "Okay, I'm having a problem with your class," or "Okay, 
I need help with this during office hours." I thank God I had a Black chemistry teacher cuz if I didn't, I probably would've never have gone to office hours cuz I would've felt like, "Oh, I'm seeming more inferior," or whatever the case may be and it's not as comfortable. I think we could benefit from more.

As noted in this quote, participants identified the complexities of attending office hours with non-Black professors. Because of the implicit biases held by some professors concerning the intellectual acumen of Black students, they felt less comfortable asking questions due to fears of being perceived as "inferior." Such dynamics are important for understanding barriers to student success for Black students. If Black students are avoiding office hours due to individual racism, they may be less likely to establish relationships with their professors and receive the academic support necessary to succeed in their courses.

\section{Limited Black Cultural Programming}

Students were also concerned about the limited Black cultural programming available at MSU. Some students reported not being aware of Black History Month events, while others argued that Black History Month should not be the only time allotted for programming related to Black culture. One student explained:

...with Black History Month. You don't always have to do it in

February. Let people know about what they do throughout the year.

Don't let it just always be a designated time...I know that month is designated for it, but obviously, the message isn't getting across if it's just within that time, within that month.

Yet, the year-round programming suggested by this participant was extremely limited at the time of the study. Two additional participants exchanged perspectives on the scarcity of Black cultural programming:

Participant A: The only thing that we do for Black History Month is with the [Multicultural Affairs office]. They have people turn in submissions for events that they wanna put on. That's based off of if people want to even do events. It's not a mandatory thing. That's 
really the only thing that's done, besides also having MLK statue in the plaza.

Participant B: That's our representation.

Participant A: Right. That's about it.

The students surmised that the Black History Month program was treated as an insignificant set of events by the larger university community. The multicultural affairs office (MAO) served as a liaison hosting an online calendar wherein individuals and organizations could identify and advertise Black History Month events, but the students perceived little intentional planning went into this process.

Another participant highlighted the paucity of Black cultural programming as a consequence of the racial composition on campus, she stated:

What I don't like-honestly, I just don't—okay, there's percentages there is-it's there. You know that there's diversity on campus, but there's just not enough inclusiveness to put that diversity to the test. Do you hear what I'm saying? The students are here, but they're not really making events or catering to the differences in that diversity. One participant described the aforementioned comment as a failure to "celebrate Black students more." Moreover, the participants reported a need for programming that would bring together the Black community. They believed this programming would generate recognition on a campus that professed to be "majority-minority" and "diverse" as well as prided themselves on closing the racial completion gap. One event that did reflect their interests was the homecoming tailgate. Some participants described this event as the first time they had encountered a significant number of Black students at Metropolitan State University:

Participant D: Yeah, the homecoming tailgate. It was Black unity.

Participant C: $\mathrm{Oh}$, it was beautiful.

Participant D: ... it was just so many Black people, and it was probably the first time seeing so many all at once united. Just events thrown by different Black organizations to come together as one.

Participant C: That was a great day. I was shocked when I saw [it]. It was so many Black people. It was like, "I need to see this every day." I loved it. 
The aforementioned comments highlight the value of representation at campus events and public spaces. As the participants reflected upon this experience, positive emotions emerged.

Lastly, participants asserted that campus partnerships may render more noteworthy programming. For example, the participants contended that more attention should be given to mental health programming concerning the Black community. One participant suggested using a model applied by the health center: "there's many organizations that partnered with the health center so why can't we do the same thing with the counseling center or the career center?" Moreover, participants felt more campus offices should conduct programming centered on Black student experiences, and partnerships may draw a larger audience as well as address the holistic needs of students including mental, physical, and professional support.

\section{A Need for Identity-Based Space}

The participants also indicated a need for spaces that were reflective of their cultural identity. For example, one participant pointed out, “... there are a lot of White spaces, [however] I can count on one hand how many known Black spaces there are on campus." When probed about which spaces on campus met this need, they identified the student union primarily, and two spaces within it: the multicultural affairs office (MAO) and a space they identified as "Wakanda" (pseudonym). As discussed previously, several participants noted that they did not learn about the MAO until later in their college careers. In fact, some were disappointed that this information had not been shared at orientation. One participant put it this way: "half of the Black students don't know about [the MAO], unfortunately." On the other hand, Wakanda was a more visible space situated at one of the entrances of the student union. Though not stated explicitly, the authors believe this location was intentional to counter the invisibility across campus felt by so many Black participants in this study.

We also found that in spaces where more visible diversity existed, participants were more likely to make friends and express feeling safe, one 
participant recounted:

I used to work in admissions. I worked there almost three years...and my supervisor made sure to have a lot of diversity. I met a lot of really close friends there. It was like that became my safe space for a period of time until new management came, and it was just a whole lot of mess. He made sure to have it as a safe space for different cultures. It was a majority Black [space], but everyone was [included]. The participant concluded that once "new management" emerged in the admissions office the environment became more complex and less conducive to a safe and diverse environment.

Black individuals were underrepresented among faculty and students, and Black cultural programming and space was scarce. As a result, participants did not feel like valued parts of the community. Some of the participants also did not believe the university was making significant efforts to create a welcoming and caring environment for Black students. As such, some participants did not have a smooth transition into MSU, and many struggled with establishing an authentic connection to the university until they were able to engage with the Black community on campus.

\section{Discussion}

The research question guiding our study explored the lived experiences of Black students transitioning into and through an institution that had successfully closed the racial completion gap. Although there was no difference in the number of degrees awarded by race, participant accounts illuminated the insidious racialized undertones and climate of the institution. Using sense of belonging as a conceptual framework, we identified four themes from participants' accounts: 1) disparate orientation and transitional experiences, 2) shortage of Black faculty, 3) limited Black cultural programming, and 4) a need for identity-based space. These four themes compounded upon one another to inhibit Black students' sense of belonging at MSU. Furthermore, the themes show how participants experienced additional complications during their transitions 
into the institution, and in some cases, made them question their decisions to persist.

A part of these accounts were participants' reports on structures (i.e., orientation, advising, and summer bridge programs) designed to mitigate the challenges of college transition (Sanford, 1966). According to the participants, these structures were not always supportive due to racialized encounters with other students and, occasionally, with staff. This finding aligns with Wilkins' (2014) research that Black students have to cope with racism as part of their transition to college, whereas White students do not have this task. Additionally, many participants in the present study reported being excluded and isolated until they found the Black community at MSU; in this way, participants did not experience a sense of belonging at MSU as a whole, rather only within the Black community. Participants also noted that they did not learn about MAO or student organizations where they might begin to connect with other Black students. Because orientation communicates institutional priorities (Mayhew, et al., 2010), these participants understood that institutional diversity and inclusion at MSU was a surface-level, rather than genuine, initiative (Boening \& Miller, 2005).

Our findings speak to the added difficulties in the transition process Black students may face as well as the opportunities to support Black students that may be missed or neglected. Such missed opportunities are particularly problematic because of the potential positive impact of orientation for students of color. Specifically, orientation may help Black students begin to build social connections (Mayhew et al., 2010), which may be even more important for marginalized populations establishing social networks (Harper, 2006; Porter \& Dean, 2015) and a sense of belonging (Walton \& Cohen, 2007). As such, orientation must provide students with ample opportunities to identify and connect with a supportive peer community. Failing to do so, as happened at MSU, means that the orientation program is not performing its key function: to prepare students for success in college. Consequently, this study also shows that even in an institution that has closed the racial completion gap, there is still much that needs to be done to improve campus climate and sense 
of belonging. Still, many participants in our study found creative ways to overcome these institutional barriers to create success without formal institutional support.

Participants' experiences were also consistent with the research on the value of Black educators. Our findings illuminated the significance of faculty identity in cultivating meaningful academic experiences (Griffin \& Reddick, 2011). Participants reported being more enthused about their learning experiences and more likely to attend office hours. Both are important aspects of student engagement (Kuh et al., 2010), which in turn supports a sense of belonging.

The last two themes highlighted how limited Black cultural programming and a need for an identity-based space further impeded participants' sense of belonging because these missing elements communicated to the students that they did not matter. These findings align with those of prior studies in that students of color benefit from engaging in homogeneous communities (Baber, 2012) and physical spaces (Linder \& Rodriguez, 2012). Even with all four of these themes illustrating an impeded sense of belonging for participants, Black students at MSU closed the completion gap.

\section{Implications}

Our findings have important implications for professional and student orientation staff. First, the experiences of participants in this study suggest that it is imperative that the orientation staff mirror the demographics of the campus community by including Black students and staff as well as those of other races and ethnicities. As such, administrators who hire professional orientation staff, including the orientation director, should be made aware of the consequences of a homogeneous orientation staff. Similarly, participants in this study highlighted that all student orientation staff should be well-trained, personable, with strong leadership skills, regardless of racial or ethnic identity, in order to facilitate relationship building between student orientation staff and orientees. Second, participants in this study pointed out the need for more attention 
to the content of orientation sessions. Though it is common practice for professional staff to have strong partnerships with student affairs offices across campus, periodic self-assessment may ensure that MAOs and Black student organizations are given sufficient attention throughout the orientation program. Such attention may include time allotted in the orientation program, student staff recruitment opportunities during a student organization or resource fair, and marketing materials distributed to orientees for reference at a later date.

Additionally, findings from this study illuminate the psychological and behavioral conditions of historically White institutions (HWI) for Black students. Many participants reported feelings of isolation and alienation due to their race as well as managing and coping with racial trauma. Findings from this study suggest that efforts to improve race relations on college campuses may be helpful in promoting a sense of belonging for students of color. To this end, previous research shows that intergroup dialogues have been an effective tool for facilitating better race relations among students (Gurin, Sorensen, Lopez, \& Nagda, 2015). Moreover, through their partnerships with other student affairs offices, orientation professionals can play a role in advocating for initiatives that improve poor racial climate such as attracting and retaining Black faculty, creating spaces for marginalized students, and extending cultural programming.

\section{References}

Baber, L. (2012). A qualitative inquiry on the multidimensional racial development among first-year African American college students attending a Predominantly White Institution. The Journal of Negro Education, 81(1), 67-81.

Boening, C. H., \& Miller, M. T. (2005). New student orientation programs

promoting diversity. The community college enterprise, 11(2), 41-50.

Brown, A. R., Morning, C., \& Watkins, C. (2005). Influence of African American engineering student perceptions of campus climate on graduation rates. Journal of Engineering Education, 94(2), 263-271. Campbell, S. D., Carter-Sowell, A. R., \& Battle, J. S. (2019). Campus climate 
comparisons in academic pursuits: How race still matters for African American college students. Group Processes \& Intergroup Relations, 22(3), 390-402.

Covarrubias, R., Gallimore, R., \& Okagaki, L. (2018). "I know that I should be here": Lessons learned from the first-year performance of borderline university applicants. Journal of College Student Retention, 20(1), 92-115.

Creswell, J. W. (2013). Research design: Qualitative, quantitative, and mixed methods approaches. 4th edition. Sage publications.

Dennis, J. M., Phinney, J. S., \& Chuateco, L. I. (2005). The role of motivation, parental support, and peer supports in the academic success of ethnic minority first-generation college students. Journal of College Student Develop, 46(3), 223-236.

Glass, C. R., Kociolek, E., Wongtrirat, R., \& Lynch, J. (2015). Uneven experiences: The impact of student-faculty interactions on international students' sense of belonging. Journal of International Students, 5(4), 353-367.

Glesne, C. (2016). Becoming qualitative researchers: An introduction (5th ed.). Upper Saddle River, NJ: Pearson.

Griffin, K. A., \& Reddick, R. J. (2011). Surveillance and sacrifice: Gender differences in the mentoring patterns of Black professors at predominantly White research universities. American Educational Research Journal, 48(5), 1032-1057.

Gurin, P., Sorensen, N., Lopez, G. E., \& Nagda, B. R. A. (2015). Intergroup dialogue: Race still matters. In Race and social problems (pp. 39-60). Springer, New York, NY.

Harper, S. (2006). Peer support for African American male college achievement: Beyond internalized racism and the burden of "acting White." The Journal of Men's Studies, 14(3), 337-358. doi:10.3149/ jms.1403.337

Hausmann, L. R. M., Schofield, J. W., \& Woods, R. L. (2007). Sense of belonging as a predictor of intentions to persist among African American and white first-year college students. Research in Higher Education, 48(7), 803-839. doi: 10.1007/s11162-007-9052-9 
Hurtado, S., \& Carter, D. F. (1997). Effects of college transition and perceptions of the campus racial climate on Latino college students' sense of belonging. Sociology of Education, 70(4), 324-345.

Johnson, D. R., Soldner, M., Leonard, J. B., Alvarez, P., Inkelas, K. K., RowanKenyon, H. T., \& Longerbeam, S. D. (2007). Examining sense of belonging among first-year undergraduates from different racial/ ethnic groups. Journal of College Student Development, 48(5), 525542. doi: $10.1353 / \operatorname{csd} .2007 .0054$

Kim, Y. K., Espinoza-Parra, O., Rennick, L. A., Franco, M. A., Dam, M. C., \& Rensberger, M. (2018). Racial differences in the effects of campus climate on sense of belonging at public research universities. In Evaluating Campus Climate at US Research Universities (pp. 233-250). Palgrave Macmillan, Cham.

Kuh, G. D., Kinzie, J., Schuh, J. H., \& Whitt, E. J. (2010). Student success in college: Creating conditions that matter. San Francisco, CA: JosseyBass.

Linder, C., \& Rodriguez, K. L. (2012). Learning from the experiences of self-identified women of color activists. Journal of College Student Development, 53(3), 383-398.

Mayhew, M. J., Vanderlinden, K., \& Kim, E. K. (2010). A multi-level assessment of the impact of orientation programs on student learning. Research in Higher Education, 51(4), 320-345.

Moustakas, C. (1994). Phenomenological research methods. Thousand Oaks, CA: Sage.

National Center for Education Statistics (2019). The Condition of Education 2019 (NCES 2019-144). Retrieved from https://nces.ed.gov/fastfacts/ display.asp?id $=40$

Nichols, A. H., Eberle-Sudre, K., \& Welch, M. (2016, March). Rising tide II: Do Black students benefit as grad rates increase? Retrieved from The Education Trust website: https://edtrust.org/resource/risingtideii/ Porter, C. J., \& Dean, L. A. (2015). Making meaning: Identity development of Black undergraduate women. NASPA Journal About Women in Higher Education, 8(2), 125-139. doi: $10.1080 / 19407882.2015 .1057164$ 
Sanford, N. (1966). Self and society. New York: Atherton Press.

St. John, E. P., Daun-Barnett, N., \& Moronski-Chapman, K. M. (2012). Public policy and higher education: Reframing strategies for preparation, access, and success. New York: Routledge.

Strayhorn, T. L. (2008). The role of supportive relationships in facilitating African American males' success in college. NASPA Journal, 45(1), 2648. doi: 10.2202/1949-6605.1906

Strayhorn, T. L. (2019). College students' sense of belonging: A key to educational success for all students. 2nd edition. New York, NY: Routledge.

Strayhorn, T. L., Lo, M. T., Travers, C. S., \& Tillman-Kelly, D. L. (2015). Assessing the relationship between well-being, sense of belonging, and confidence in the transition to college for Black male collegians. Spectrum: A Journal on Black Men, 4(1), 127-138.

Vaccaro, A., \& Daly-Cano, M., \& Newman, B. M. (2015). A sense of belonging among college students with disabilities: An emergent theoretical model. Journal of College Student Development, 56 (7), 670-686.

Walton, G. M., \& Cohen, G. L. (2007). A question of belonging: Race, social fit, and achievement. Journal of Personality and Social Psychology, 92(1), 82-96.

White, E., \& Schulenberg, J. (2012). Academic advising-a focus on learning. About Campus, 16(6), 11-17.

Wilkins, A. C. (2014). Race, age, and identity transformations in the transition from high school to college for Black and first-generation White men. Sociology of Education, 87(3), 171-187.

Zhang, P., \& Smith, W. (2011). From high school to college: The transition experiences of Black and White students. Journal of Black Studies, 42(5), 828-845.

Acknowledgement: Special thanks to Vanity Shields for their work annotating sources ultimately used in our literature review. 


\section{Appendix A}

Table 1. Summary of Participant Demographics

Characteristic

Number of Students

\section{Class}

First-year

2

Sophomore 3

Junior

Senior

14

Second Degree

First Generation

Yes

7

No

20

Gender Identity

Woman, Cisgender 22

Man, Cisgender 4

Genderqueer 1

Racial/Ethnic Identity

Black/African American 14

Black \& Caribbean 9

African 1

Afro-Latinx 1

Hebrew 1

Unreported 1

Major

Business

4

Communication 3

STEM 6

Humanities 2

Medicine \& Health 6

$\begin{array}{ll}\text { Social Sciences } & 7\end{array}$

Natural Sciences 3 